\title{
Streefwaarden voor de volksgezondheid
}

\author{
Jochen O. Mierau • Brigit C.A. Toebes (D)
}

Geaccepteerd op: 24 februari 2021 / Published online: 26 maart 2021

(C) The Author(s) 2021

Samenvatting In deze bijdrage breken wij een lans voor wettelijk verankerde streefwaarden voor de volksgezondheid, analoog aan de milieuwetgeving. Aanknopingspunten hiertoe zijn te vinden in internationale en nationale beleidsafspraken, zoals de Duurzame ontwikkelingsdoelen en het Nationaal Preventieakkoord. Wettelijke verankering is minder vrijblijvend en biedt een mogelijkheid om de overheid ter verantwoording te roepen.

Trefwoorden benchmarks volksgezondheid . indicatoren - wetgeving - recht op gezondheid . Duurzame ontwikkelingsdoelen

\begin{abstract}
This contribution advocates embedding public health benchmarks in Dutch legislation, analogous to the Dutch environmental legislation. International and national policy statements including the Sustainable Development Goals offer a basis for identifying such benchmarks. The legislative basis offers a ground for holding government to account in case of a failure to meet its public health goals.
\end{abstract}

Keywords Public health benchmarks · Indicators • Public health legislation - Right to health . Sustainable Development Goals

\footnotetext{
Prof.dr. J. Mierau

Faculteit Economie en Bedrijfskunde, Rijksuniversiteit Groningen, Groningen, Nederland
}

Prof.dr. J. Mierau • Prof.mr.dr. B. Toebes ( $\square)$

Aletta Jacobs School of Public Health (AJSPH), Groningen,

Nederland

b.c.a.toebes@rug.nl

Prof.mr.dr. B. Toebes

Faculteit Rechtsgeleerdheid, Rijksuniversiteit Groningen, Groningen, Nederland

\section{Inleiding}

Trendmatige volksgezondheidsindicatoren laten de afgelopen jaren een neerwaartse tendens zien. Zo is het deel van de bevolking met obesitas sterk aan het toenemen en zijn de gezondheidsverschillen tussen laag- en hoogopgeleide Nederlanders de afgelopen jaren groter geworden (zie fig. 1). Vooralsnog heeft overheidsbeleid het tij niet weten te keren. De vraag nu is welke mogelijkheden de overheid ter beschikking heeft om de volksgezondheid duurzaam te bevorderen. In deze bijdrage breken wij een lans voor wettelijke verankering van streefwaarden voor de volksgezondheid, analoog aan de milieuwetgeving.

\section{Normen en streefwaarden}

In deze bijdrage sluiten we aan bij de gangbare terminologie uit de milieuwetgeving en maken we onderscheid tussen normen en streefwaarden. Met normen bedoelen we gedragsvoorschriften voor de overheid. Internationale mensenrechten en nationale grondrechten bevatten belangrijke normen als het gaat om de volksgezondheid. Een belangrijke norm is het recht op gezondheid, dat is verankerd in een aantal internationale mensenrechtenverdragen die door Nederland zijn geratificeerd. Voorbeelden zijn artikel 12 van het Internationale Verdrag inzake Economische, Sociale en Culturele Rechten en artikel 24 van het Kinderrechtenverdrag. Ook onze grondwet benadrukt de verantwoordelijkheid van de overheid om de volksgezondheid te bevorderen (artikel 22-1), een bepaling die nader uitgewerkt wordt in de stelselwetten, met name de Zorgverzekeringswet, de Wet langdurige zorg, de Wet maatschappelijke ondersteuning, de Jeugdwet en de Wet Publieke gezondheid. Ook worden tal van aan gezondheid gerelateerde zaken geregeld in, onder meer, de Omgevingswet, de 
Figuur $1 \quad$ Ontwikkeling van obesitas (BMI $>30$ ), uitgesplitst naar opleidingsniveau in de afgelopen twintig jaar

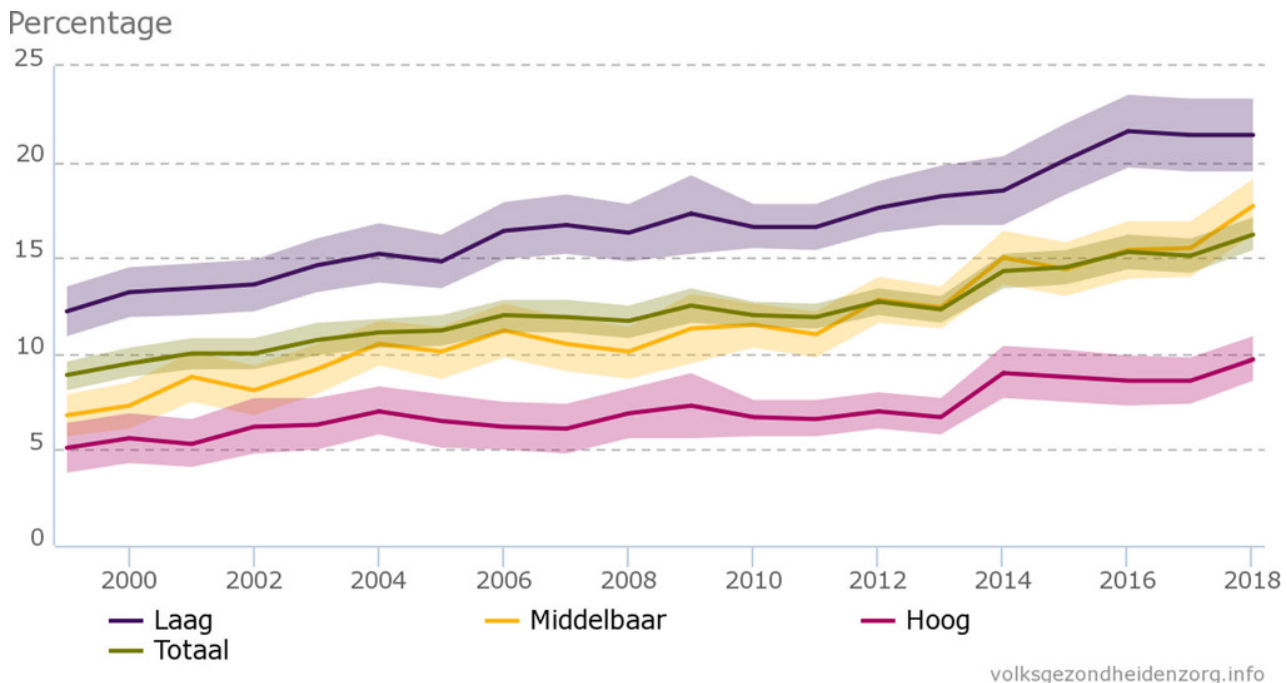

Arbeidsomstandighedenwet en verschillende warenwetten.

Uit deze internationale en nationale normen en wetgeving vloeien echter geen streefwaarden voort, dat wil zeggen concrete kwantitatieve doelstellingen in termen van meetbare indicatoren, die binnen een aantal jaren gehaald dienen te worden. Grond- en mensenrechten richten zich in algemene en normatieve zin op het beschermen van de menselijke waardigheid (human dignity). Dat is een breed begrip, dat waarden omvat als bescherming van de persoonlijke levenssfeer, fysieke integriteit en vrijheid van meningsuiting, en gezondheidsbescherming. Concrete gezondheidswetten reguleren specifieke aspecten van de volksgezondheid, zoals de toegang tot de zorg en infectieziektebestrijding. Ze bieden echter evenmin streefwaarden. Er zijn weliswaar tal van kwaliteitskaders en richtlijnen die de uitvoering van zorghandelingen beschrijven, maar er is geen streefwaarde voor wat het 'niveau' van volksgezondheid is dat wordt nagestreefd, laat staan dat er interventiewaarden zijn waarboven maatregelen genomen moeten worden om weer binnen de streefwaarde te komen.

Het drieluik norm, streefwaarde en interventiewaarde kan aan de hand van een fictief voorbeeld worden verhelderd. De norm voor gezondheidsbescherming uit artikel 22-1 van de grondwet zou kunnen worden vertaald naar een wettelijk verankerde streefwaarde voor het maximale percentage mensen dat in een bepaalde regio overgewicht mag hebben, laten we zeggen $20 \%$. Er zou dan een interventiewaarde kunnen worden vastgesteld op $18 \%$, wat betekent dat als het aantal mensen met overgewicht de $18 \%$ overschrijdt, de overheid maatregelen moet nemen om niet na verloop van tijd de streefwaarde te overschrijden. Bij streefwaarden gaat het dus nadrukkelijk niet om een vaste verzameling aan interventies die wordt uitgerold, maar om het creëren van de wettelijk druk om interventies in te gaan zetten.
Wij pleiten in deze bijdrage daarom voor het wettelijk verankeren van streefwaarden. Het voordeel van streefwaarden met wettelijke verankering in aanvulling op een beleidsmatige aanpak is dat ze handvatten bieden om de overheid ter verantwoording te roepen en tot handelen te dwingen. Een intentie kan onder druk vloeibaar worden, terwijl een wettelijke verankering afdwingbaar is, tenzij de wet wordt gewijzigd. In die zin kunnen wettelijk verankerde streefwaarden complementair zijn aan de huidige beleidsaandacht voor volksgezondheid in het algemeen, en gezondheidsbevordering in het bijzonder. Immers, doordat een wettelijk verankerde streefwaarde minder vrijblijvend is, zal bestuurlijke aandacht veel meer gericht blijven op het binnen de streefwaarden blijven, en niet op het zoeken naar manieren om te verbloemen dat beleidsdoelen niet gehaald worden. Dit kan eveneens tot uiting komen in de (financiële) middelen die aan volksgezondheidsbeleid worden toegewezen. Mocht een streefwaarde niet gehaald worden, waardoor additionele beleidsmatige aandacht noodzakelijk is, dan kan dat aanleiding vormen voor het opnieuw toewijzen van middelen richting volksgezondheidsbeleid of het ophogen van het totale budget van de gemeenten (via gemeentelijke belastingen of bijdragen uit het gemeentefonds).

\section{Milieuwetgeving}

Binnen de milieuwetgeving zijn streefwaarden heel gangbaar. Zo dient de concentratie van tal van stoffen in de lucht, het grondwater, het riool, de grond en vele andere plekken nauwkeurig te worden bijgehouden en worden deze afgezet tegen nauwkeurig bepaalde interventiewaarden. Overschrijding van deze waarden leidt dikwijls tot interventies om weer onder de streefwaarden te komen en het is gangbaar beleid om streefwaarden in de tijd aan te scherpen om meer milieuwinst te realiseren (box 1). Om dit zo fijnmazig te kunnen meten is er jarenlang geïnvesteerd in een 


\section{Box 1 Casus: Programma Aanpak Stikstof}

In 2015 trad het Programma Aanpak Stikstof (PAS) in werking, een beleidskader om de natuur te beschermen in de door Nederland aangewezen natuurgebieden van het Europese Natura 2000-programma. Het PAS was een antwoord op de vele procedures die tegen de staat gevoerd werden vanwege het overschrijden van de Europese normen voor de hoeveelheid stikstofdioxide die in de lucht aanwezig mag zijn. Het doel van de normen was om de stikstofdepositie in de aangewezen natuurgebieden te verminderen, omdat stikstofoxiden en ammoniak de natuur bedreigen.

Op 29 mei 2019 verklaarde de Raad van State het gebruik van het PAS bij vergunningverlening ongeldig. Het door de overheid opgezette beleidskader in de vorm van het PAS voldeed volgens de Raad van State nog steeds niet aan de Europese regels (habitatrichtlijn), zoals die al eerder door het Europese Hof van Justitie waren bevestigd. Omdat zo'n 18.000 plannen moesten worden stilgelegd, leidde dit tot de stikstofcrisis.

Om alsnog aan de Europese normen te voldoen werd vervolgens in hoog tempo gewerkt aan noodmaatregelen die niet per se in lijn waren met de politieke voorkeuren van het zittende kabinet. Zo werd de maximumsnelheid op snelwegen teruggebracht naar $100 \mathrm{~km} / \mathrm{u}$ - nota bene door een regering die hem eerst had verhoogd.

Deze casus laat zien dat het wettelijk vastleggen van normen (in dit geval op Europees niveau) kan leiden tot interventies die zonder deze normen waarschijnlijk niet tot stand waren gekomen.

nauwkeurige infrastructuur van meetapparaten, netwerken en IT-systemen die de milieusituatie in Nederland hoogfrequent kunnen weergeven.

Het is hierbij van belang dat streefwaarden voor milieu onder de verantwoordelijkheid vallen van een (gekozen) bestuurder die hierop aangesproken kan worden - bijvoorbeeld door een rechter, zoals de casus in box 1 laat zien. Dit leidt ertoe dat middelen worden vrijgemaakt om interventies te ontwerpen die ervoor zorgen dat de streefwaarden gehaald worden. Deze dynamiek is cruciaal omdat het de verplichting ten aanzien van het halen van streefwaarden vertaalt in concrete interventies. De vergelijking met streefwaarden voor milieu laat zien dat het instellen van streefwaarden het gedrag van overheden kan beïnvloeden om beleidsdoelen te halen.

Ook (internationale) doelstellingen kunnen aanleiding geven tot het aanpassen van beleid. Zo is er een grote hoeveelheid internationale verdragen die beogen de opwarming van de aarde tegen te gaan. Deze verdragen verplichten de verdragsstaten om de verplichtingen uit het verdrag via wetgeving en beleid naar interventies te vertalen. De Aardetop in Rio de
Janeiro in 1992 leidde tot de aanname van het VNKaderverdrag over Klimaatverandering (UNFCCC) en de Agenda 21, een ambitieus programma om in de 21ste eeuw tot duurzame ontwikkeling te komen. Vervolgens werd onderhandeld over streefwaarden om de uitstoot van broeikassen te verminderen, die met het Kyotoprotocol in 2005 van kracht werden. De klimaatconferentie van Parijs 2015 leidde tot de aanname van het Akkoord van Parijs, een internationaal verdrag om de opwarming van de aarde terug te dringen.

Inmiddels is duidelijk dat veel van deze doelstellingen internationaal niet worden gehaald. Niettemin kunnen de doelstellingen uit de verdragen leiden tot beleidswijzigingen op nationaal niveau. De uitspraak van de Nederlandse rechter in de Urgenda-zaak laat zien dat internationaal afgesproken streefwaarden een nationale overheid kunnen dwingen tot overheidsinterventies gericht op het nastreven van deze doelstellingen. De concrete uitkomst van de Urgenda-zaak is dat de Nederlandse Staat verplicht is om de uitstoot van broeikasgassen vanaf Nederlandse bodem per eind 2020 met minstens $25 \%$ te verminderen ten opzichte van 1990. De maatregelen die het kabinet heeft genomen voor de uitvoering van de Urgendazaak worden uitvoering beschreven in een Kamerbrief van het Ministerie van Economische Zaken en Klimaat. De Urgenda-zaak laat duidelijk zien hoe een streefwaarde die door de rechter werd bekrachtigd beleidsmakers ertoe heeft aangezet om een andere richting in te slaan.

\section{Streefwaarden voor de volksgezondheid}

Vanuit deze achtergrond is de analogie naar volksgezondheidsstreefwaarden snel gemaakt. We wijzen in dit kader op een gezaghebbende aanbeveling bij het internationale recht op gezondheid (Algemene aanbeveling 14) [1]. Deze aanbeveling moedigt lidstaten aan om gezondheidsbeleid te koppelen aan indicatoren en benchmarks, dat wil zeggen referentiewaarden voor streefwaarden zoals hierboven beschreven. Die zijn in Nederland echter niet vastgelegd, laat staan wettelijk verankerd. De kaders daarvoor zijn er wel.

Er bestaan reeds internationale doelstellingen voor het bevorderen van de volksgezondheid waar Nederland zich aan heeft gecommitteerd. De gezaghebbende Duurzame ontwikkelingsdoelen (Sustainable Development Goals), in 2016 vastgesteld door de Verenigde Naties, betreffen een aantal doelen voor 2030. Zo is gezondheid geborgd in Sustainable Development Goal 3: 'ensure healthy lives and promote well-being for all at all ages', met als concreet doel een derde reductie van vroegtijdig overlijden vanwege niet-overdraagbare aandoeningen door preventie en zorg.

In Nederland is deze doelstelling vertaald naar de Centrale Gezondheidsmissie van het Ministerie van Economische Zaken en Klimaat [2]. Deze missie stelt dat alle Nederlanders in 2040 vijf jaar langer in goede 
gezondheid leven en dat de gezondheidsverschillen tussen de laagste en de hoogste sociaal-economische groepen met $30 \%$ zijn afgenomen. Het is niet de eerste keer dat Nederland zich committeert aan een kwantitatieve doelstelling voor een indicator van volksgezondheid. Tot nu toe zijn deze doelen echter nooit gehaald.

In 2018 sloot de Rijksoverheid het Nationaal Preventieakkoord, met daarin afspraken over het terugdringen van ongezond gedrag, waaronder een prijsverhoging van tabak, gezondere scholen en beperking van prijsacties van producten met alcohol. Meer dan zeventig verschillende organisaties onderschreven deze afspraken. Het akkoord vormt een doorbraak als het gaat om het bespreekbaar maken van ongezond gedrag in de samenleving. Het akkoord is echter ook een compromis door de deelname van een veelheid aan partijen, en bevat geen streefwaarden, zoals wij in deze bijdrage voorstaan [3]. Niettemin bevat het akkoord een aantal doelstellingen die aanknopingspunten kunnen vormen voor de te formuleren streefwaarden, zoals het streven naar een daling van het percentage volwassenen met obesitas van de huidige $14,5 \%$ naar $7,1 \%$ (het niveau van 1995).

Om een volgende keer de doelstellingen wél te halen stellen we voor om dergelijke doelstellingen via streefwaarden voor de volksgezondheid in de wet te verankeren, zoals dat nu ook met milieunormen gebeurt. Mierau vroeg hier vorig jaar aandacht voor in het publieke debat [4], Zorgverzekeraar Menzis heeft opgeroepen tot een gezondheidsplicht voor zorgverzekeraars als aanvulling op de zorgplicht die reeds in de Zorgverzekeringswet (Zvw) is verankerd [5] en de Tweede Kamer nam onlangs een motie aan die de overheid oproept om uit te zoeken hoe wettelijke gezondheidsdoelen kunnen worden verankerd [6].

De coronapandemie heeft laten zien op welke manier streefwaarden van invloed zijn op het maken van volksgezondheidsbeleid. Door te sturen op de zorgcapaciteit wordt het aantal beschikbare IC-bedden een harde beperking voor het aantal mensen dat met corona besmet mag worden. Het onder een bepaalde bezettingsgraad houden van de IC-capaciteit is dus de streefwaarde van het beleid. Wanneer de capaciteit uitgeput dreigt te raken, worden vergaande maatregelen genomen om weer binnen de streefwaarde te komen. Hoewel dit een extreem voorbeeld is, laat het zien dat als beperkingen niet op de korte termijn opgerekt kunnen worden (zoals de IC-capaciteit), beleidsaandacht en -innovatie gericht worden op het halen van de streefwaarde. In dit geval via tal van maatregelen die we in Nederland niet eerder gezien hebben. Wettelijk verankerde streefwaarden voor de volksgezondheid voor bijvoorbeeld het percentage mensen met overgewicht zijn weliswaar geen infrastructurele beperking zoals het aantal IC-bedden, maar ze leggen wel een verantwoordelijkheid op om beleid te voeren dat ervoor moet zorgen dat indicatoren binnen hun streefwaarde blijven.

\section{Besluit}

Het opstellen van streefwaarden voor milieudoelstellingen heeft geleid tot meer aandacht voor het milieu. En toen de overheid het milieu uit het oog verloor, speelde de rechter een corrigerende rol. Wij suggereren dat eenzelfde dynamiek, via het verankeren van streefwaarden voor de volksgezondheid, beleidsmakers kan dwingen om de volksgezondheid concreet te bevorderen. De vraag is echter hoe we dit handen en voeten kunnen geven. Volksgezondheidsbeleid is notoir complex, kent veel belanghebbenden en doorkruist tal van wetten. Op de weg naar het effectief gebruiken van streefwaarden moeten volgens ons vier stappen worden gezet:

\section{Wetgeving}

Een wetswijziging dient de streefwaarden wettelijk te verankeren. Artikel 3.1 van de Wet publieke gezondheid verplicht de Minister om de kwaliteit en doelmatigheid van de publieke gezondheidszorg te bevorderen en om hiertoe interdepartementaal en internationaal samen te werken. Aan deze bepaling zou een derde lid toegevoegd kunnen worden dat deze doelstelling concretiseert: 'Onze Minister legt de doelstellingen voor bevordering van kwaliteit en doelmatigheid van de publieke gezondheidszorg vast in meetbare indicatoren en streefwaarden en legt hierover verantwoording af'.

Deze wetswijziging verplicht de doelmatigheid van beleid kwantitatief te volgen en creëert meer bestuurlijke aandacht voor volksgezondheid.

\section{Vastleggen van streefwaarden}

Daarna, of tegelijkertijd, moet bepaald worden voor welke indicatoren streefwaarden vastgelegd worden. Denkbaar is om - geïnspireerd door de internationale doelstellingen - een viertal indicatorengroepen aan te wijzen die op groeps- en/of gebiedsniveau worden gevolgd en waarvoor streefwaarden worden geformuleerd. Te denken valt aan:

- ervaring - ervaren (mentale en fysieke) gezondheid; - ziekte - aantal mensen met chronische ziekten en/of mentale aandoeningen;

- leefstijl-aantal mensen met obesitas, aantal rokers, enzovoort;

- kosten - zorgkosten in verschillende domeinen.

In het kort: hoe gaat het, wat heb je, wat doe je en wat kost het? Met de doelstellingen zoals deze zijn vastgelegd in het Nationaal Preventieakkoord als voorbeeld zou dan op nationaal niveau het streven kunnen zijn om te komen tot een reductie van bijvoorbeeld obesitas naar het niveau van 1995. Dit laat zich tevens gemakkelijk vertalen naar regionaal beleid (dat wil zeggen gemeentelijk en, liefst, wijkniveau). Tevens kunnen de indicatoren worden uitgesplitst naar inko- 
mens- en/of opleidingsgroepen, om zo zicht te houden op de ontwikkeling van gezondheidsverschillen.

\section{Monitoren van streefwaarden}

Een praktische uitdaging is om de indicatoren die aan de streefwaarden ten grondslag liggen systematisch te meten. Ook hier ligt de vergelijking met de milieuwetgeving voor de hand, waar een fijnmazig netwerk van meetpunten de luchtkwaliteit in heel Nederland bijhoudt. In vergelijking daarmee staat het monitoren van de volksgezondheid in Nederland nog in de kinderschoenen. Het vastleggen van streefwaarden kan een impuls vormen voor het beter meten van de volksgezondheid. Een begin kan gemaakt worden met de gegevens uit de Staat van Volksgezondheid, de Gezondheidsenquête en de Gezondheidsmonitor van de GGD'en, het RIVM en het CBS. Meer frequente en fijnmazige gegevens zouden ontleend kunnen worden aan de vele registratiegegevens die verzameld worden als onderdeel van de gezondheidsadministratie (denk aan zorgkosten en ICD-codes).

\section{Interveniëren}

Streefwaarden zijn natuurlijk nog geen interventies in bijvoorbeeld de leefstijl, leefomgeving en organisatie van zorg en welzijn. Met herkenbare streefwaarden voor de volksgezondheid worden de overheid en haar uitvoeringsorganisaties echter gedwongen om interventies te ontwikkelen, te implementeren en te evalueren. Daarnaast kunnen streefwaarden voorkomen dat er interventies worden uitgevoerd die niet stroken met andere normen en wetten. De overheid wordt er immers juist toe aangezet om binnen de haar beschikbare kaders te zoeken naar bestaande en nieuwe manieren om de volksgezondheid duurzaam te verbeteren. Doordat streefwaarden het gebruik en de ontwikkeling van bewezen effectieve interventies bespoedigen, kunnen ze een waardevolle aanvulling vormen op bestaande maatregelen.

Dankbetuiging Met dank aan Jos Dute, Marlies Hesselman, Frank Nelissen en Scott Burris voor waardevolle opmerkingen en suggesties.
Open Access This article is licensed under a Creative Commons Attribution 4.0 International License, which permits use, sharing, adaptation, distribution and reproduction in any medium or format, as long as you give appropriate credit to the original author(s) and the source, provide a link to the Creative Commons licence, and indicate if changes were made. The images or other third party material in this article are included in the article's Creative Commons licence, unless indicated otherwise in a credit line to the material. If material is not included in the article's Creative Commons licence and your intended use is not permitted by statutory regulation or exceeds the permitted use, you will need to obtain permission directly from the copyright holder. To view a copy of this licence, visit http://creativecommons.org/licenses/by/4.0/.

\section{Literatuur}

1. UN Committee on Economic, Social and Cultural Rights (CESCR). General Comment No. 14: the right to the highest attainable standard of health (Art. 12 of the Covenant), 11 August 2000, E/C.12/2000/4.. https://www.refworld.org/ docid/4538838d0.html. Geraadpleegd op: 18jan 2021.

2. Ministerie van Economische Zaken en Klimaat. Missies voor het topsectoren- en innovatiebeleid.. https:// www.rijksoverheid.nl/documenten/publicaties/2019/04/ 26/missies (Gecreëerd: 26 apr 2019). Geraadpleegd op: 16 jan 2020.

3. Toebes B, Gispen ME, Dietvorst R, et al. Ongezond gedrag: de rol van het recht. Preadvies Vereniging voor Gezondheidsrecht. Den Haag: SDU;2019.

4. Mierau JO. Niemand draagt verantwoordelijkheid voor volksgezondheid. Zorgvisie.nl.. https://www.zorgvisie. $\mathrm{nl} /$ mierau-niemand-draagt-verantwoordelijkheid-voorvolksgezondheid/ (Gecreëerd: 25 aug 2020). Geraadpleegd op: 18 nov 2021.

5. Menzis. Samenwerken aan gezonde regio's. Wageningen: Menzis. 2020. https://www.menzis.nl/ over-menzis/- /m/publieke-sites/over-menzis/paginas/ bestanden/samenwerken-aan-gezonde-regios/nota-sam enwerken-aan-gezonde-regios.pdf. Geraadpleegd op: 19 feb 2021.

6. Kuiken A, Renkema W-J. Gewijzigde motie van de leden Kuiken en Renkema over het wettelijk verankeren van collectieve gezondheidsdoelen. Den Haag: Tweede Kamer der Staten Generaal. 2021. https://www.tweedekamer.nl/ kamerstukken $/$ moties $/$ detail?id=2021Z02160\&did=2021D 04772. Geraadpleegd op: 19 feb 2021. 